\title{
$\alpha$-Mangostin Improves Glucose Uptake and Inhibits Adipocytes Differentiation in 3T3-L1 Cells via PPAR $\gamma$, GLUT4, and Leptin Expressions
}

\author{
Muhammad Taher, ${ }^{1}$ Mohamed Zaffar Ali Mohamed Amiroudine, ${ }^{1}$ \\ Tengku Muhamad Faris Syafiq Tengku Zakaria, ${ }^{1}$ Deny Susanti, ${ }^{2}$ Solachuddin J. A. Ichwan, ${ }^{3}$ \\ Mohd Arifin Kaderi, ${ }^{4}$ Qamar Uddin Ahmed, ${ }^{5}$ and Zainul Amiruddin Zakaria ${ }^{6}$ \\ ${ }^{1}$ Department of Pharmaceutical Technology, Faculty of Pharmacy, International Islamic University Malaysia, Jalan Istana, \\ Bandar Indera Mahkota, 25200 Kuantan, Pahang, Malaysia \\ ${ }^{2}$ Department of Chemistry, Faculty of Science, International Islamic University Malaysia, Jalan Istana, Bandar Indera Mahkota, \\ 25200 Kuantan, Pahang, Malaysia \\ ${ }^{3}$ Faculty of Dentistry, International Islamic University Malaysia, Jalan Istana, Bandar Indera Mahkota, 25200 Pahang, Malaysia \\ ${ }^{4}$ Faculty of Allied Health Science, International Islamic University Malaysia, Jalan Istana, Bandar Indera Mahkota, \\ 25200 Kuantan, Pahang, Malaysia \\ ${ }^{5}$ Department of Pharmaceutical Chemistry, Faculty of Pharmacy, International Islamic University Malaysia, Jalan Istana, \\ Bandar Indera Mahkota, 25200 Kuantan, Pahang, Malaysia \\ ${ }^{6}$ Department of Biomedical Sciences, Faculty of Medicine and Health Sciences, Universiti Putra Malaysia, 43400 Serdang, \\ Selangor, Malaysia
}

Correspondence should be addressed to Muhammad Taher; tahermuhammad@gmail.com and Zainul Amiruddin Zakaria; dr_zaz@yahoo.com

Received 28 September 2014; Revised 25 February 2015; Accepted 26 February 2015

Academic Editor: Adeolu Alex Adedapo

Copyright (C) 2015 Muhammad Taher et al. This is an open access article distributed under the Creative Commons Attribution License, which permits unrestricted use, distribution, and reproduction in any medium, provided the original work is properly cited.

\begin{abstract}
Obesity has been often associated with the occurrence of cardiovascular diseases, type 2 diabetes, and cancer. The development of obesity is also accompanied by significant differentiation of preadipocytes into adipocytes. In this study, we investigated the activity of $\alpha$-mangostin, a major xanthone component isolated from the stem bark of $G$. malaccensis, on glucose uptake and adipocyte differentiation of 3T3-L1 cells focusing on PPAR $\gamma$, GLUT4, and leptin expressions. $\alpha$-Mangostin was found to inhibit cytoplasmic lipid accumulation and adipogenic differentiation. Cells treated with $50 \mu \mathrm{M}$ of $\alpha$-mangostin reduced intracellular fat accumulation dose-dependently up to $44.4 \%$ relative to MDI-treated cells. Analyses of 2 -deoxy-D- $\left[{ }^{3} \mathrm{H}\right]$ glucose uptake activity showed that $\alpha$ mangostin significantly improved the glucose uptake $(P<0.05)$ with highest activity found at $25 \mu \mathrm{M}$. In addition, $\alpha$-mangostin increased the amount of free fatty acids (FFA) released. The highest glycerol release level was observed at $50 \mu \mathrm{M}$ of $\alpha$-mangostin. qRT-PCR analysis showed reduced lipid accumulation via inhibition of PPAR $\gamma$ gene expression. Induction of glucose uptake and free fatty acid release by $\alpha$-mangostin were accompanied by increasing mRNA expression of GLUT4 and leptin. These evidences propose that $\alpha$-mangostin might be possible candidate for the effective management of obesity in future.
\end{abstract}

\section{Introduction}

The incidence of obesity has become a major public health concern worldwide. Obesity is characterised by the accumulation and deposition of excess fat in adipose tissues [1] and increased deposition of cytoplasmic triglycerides [2], which may lead to various metabolic and chronic diseases such as cardiovascular diseases, type 2 diabetes, and cancer [3]. The development of obesity in adults is also accompanied by significant differentiation of preadipocytes into adipocytes [4].

In recent years, research studies on adipocytes have been growing tremendously. Accordingly, adipocytes are emerging 
as a major drug target for diabetes and obesity-mediated metabolic syndrome [5]. Adipose is not only known for its capacity to store the excess of dietary energy in the form of triglyceride [6], but has also been acknowledged to play an important role in the control of energy metabolism [7, 8]. A number of transcription factors have been documented to be involved in the adipogenesis, glucose uptake, and glycolysis pathway [9]. These transcription factors include peroxisome proliferator-activated receptor- $\gamma$ (PPAR $\gamma)$, glucose transporter-4 (GLUT4), and adipokines such as leptin.

$\operatorname{PPAR} \gamma$ is predominantly expressed in adipose tissues and plays a central role in adipose tissue functions [10]. PPAR $\gamma$ regulates the expression of genes associated with insulin signalling and glucose and lipid metabolism in mature adipocytes [11]. Reduced expression of PPAR $\gamma$ has been shown to be effective in inhibiting the adipogenesis of 3T3L1 cells [12]. GLUT4 is a high-affinity glucose transporter predominantly expressed in insulin-sensitive tissues such as muscle and adipocytes [13]. Increased expression and plasma membrane translocation of GLUT4 have been found to lower blood glucose and enhance glucose transport and utilisation [14]. Leptin is produced mainly by adipocytes and found in low levels in the gastric fundic epithelium, intestine, skeletal muscle, mammary epithelium, placenta, and brain [15]. High levels of circulating leptin in adipose tissues characterise human obesity [16] and increased levels of body fat [17]. As a result, the role of some gene expressions and the importance of these expressions have been studied.

A detailed review of the literature shows that a few species of Garcinia have attracted the attention of health practitioners [18]. For example, the fruit of G. cambogia has been shown to have antiobesity effect $[19,20]$, affect the lipid metabolism [21], and inhibit the cytoplasmic lipid accumulation as well as adipogenic differentiation of preadipocytes [22]. Moreover, water-soluble calcium hydroxycitrate (HCA) as G. atroviridis has been used for the treatment of obese women [23], while G. indica (hydroxycitric acid) has been used as a weight loss supplement for obese patients [24]. Due to the presence of active compounds in different Garcinia species, Garcinia has been regarded as an interesting choice to be studied further. The species of Garcinia have been reported to possess a lot of bioactive molecules such as xanthones, flavonoids, benzophenones, lactones, and phenolic acids [25]. Recently, the stem bark of $G$. malaccensis has been shown to contain xanthones, namely, $\alpha$-mangostin as the major compound [26]. Interestingly, the most studied xanthone of Garcinia species is $\alpha$-mangostin for which antibacterial [27], antioxidant [28], anti-inflammatory [29-31], antiproliferative [32], proapoptotic [33-35], and anticarcinogenic [36-39] activities have already been reported.

This paper reports the effect of $\alpha$-mangostin isolated from the stem bark of G. malaccensis on 3T3-L1 adipocytes via the adipogenesis and glucose uptake activity. In this study, we evaluated the effect of $\alpha$-mangostin on the cell viability based on the MTT assay and quantification of lipid accumulation in 3T3-L1 cells. We also examined insulininduced glucose uptake into 3T3-L1 adipocytes as a measure by the liquid scintillation counter. Finally, qRT-PCR analysis was performed in order to find out the gene expression

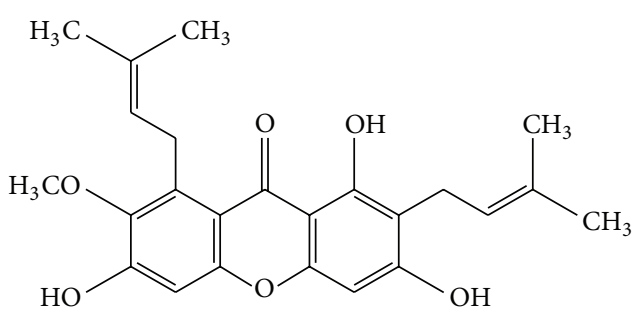

(a)

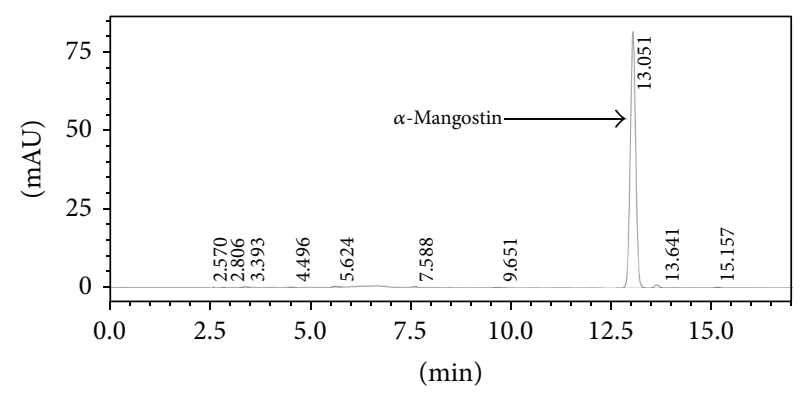

(b)

FIgURE 1: The purity of $\alpha$-mangostin was determined using HPLC analysis. (a) Chemical structure of $\alpha$-mangostin. (b) The amount was measured by HPLC technique. The peak of $\alpha$-mangostin was observed at retention time of $13.05 \mathrm{~min}$.

responsible for the $\alpha$-mangostin ability to reduce lipid accumulation in adipose tissues. As a result, we demonstrated that $\alpha$-mangostin may reduce lipid accumulation as well as stimulate glucose uptake by the cells and may be a promising candidate as an antiobesity agent.

\section{Materials and Methods}

2.1. Plant Materials and Isolation of $\alpha$-Mangostin. $\alpha$ Mangostin was isolated from G. malaccensis [26]. The purity of the isolated $\alpha$-mangostin was approximately $94 \%$ as identified by HPLC (Figure 1) and compared to the reference standard of purity $96.5 \%$ of $\alpha$-mangostin $\left(\mathrm{C}_{24} \mathrm{H}_{26} \mathrm{O}_{6}\right)$ from ChromaDex (Irvin, CA) [40]. Mouse 3T3-L1 fibroblast (CL-173) was obtained from the American Type Culture Collection (ATCC), Virginia, USA.

2.2. HPLC Analysis. Quantification of $\alpha$-mangostin was performed according to method described by Elsaid Ali et al. [40]. The HPLC system (Shimadzu, Japan) consisted of a quaternary pump (LC-20AT), autosampler (SIL-20A HT), solvent degasser unit (DGU-20A 5R), diode array detector (SPD-M20A), and column oven (CTO-10AS VP). The quantification wavelength of $\alpha$-mangostin was set at $316 \mathrm{~nm}$. The chromatographic separation was performed at ambient temperature $\left(25-28^{\circ} \mathrm{C}\right)$ using Hypersil BDS $\mathrm{C}_{18}$ column (4.6 $\times 100 \mathrm{~mm}, 3 \mu \mathrm{m}$ size) (Thermo Scientific, USA) with $\mathrm{C}_{18}$ guard column. The mobile phase consisted of acetonitrile (A) and $0.1 \%(\mathrm{v} / \mathrm{v})$ orthophosphoric acid $\left(\mathrm{H}_{3} \mathrm{PO}_{4}\right)$ diluted in water $(\mathrm{B})$ was delivered at flow rate of $1.0 \mathrm{~mL} / \mathrm{min}$ following programmed gradient elution: 70\% (A) isocratic for $6 \mathrm{~min}$, 
TABle 1: Differentiation scheme of adipocytes.

\begin{tabular}{lccc}
\hline Day & Negative control & Positive control & Treatment group \\
\hline & & Dexamethasone $(0.25 \mu \mathrm{M})$ & Dexamethasone $(0.25 \mu \mathrm{M})$ \\
& No inducer (solvent 0.1\% ethanol) & IBMX $(0.5 \mathrm{mM})$ & IBMX $(0.5 \mathrm{mM})$ \\
& & Insulin $(1.0 \mu \mathrm{g} / \mathrm{mL})$ & $\alpha$-Mangostin $(10,20,50 \mu \mathrm{M})$ \\
\hline 2 & No inducer (solvent 0.1\% ethanol) & Insulin $(100 \mathrm{nM})$ & Insulin $(100 \mathrm{nM})$ \\
\hline $4-8$ & Complete medium & Complete medium & Complete medium \\
\hline
\end{tabular}

$70-75 \%(\mathrm{~A})$ in $1.2 \mathrm{~min}, 75-80 \%$ (A) in $0.4 \mathrm{~min}, 80 \%(\mathrm{~A})$ isocratic for $2.4 \mathrm{~min}, 80-70 \%$ (A) in $0.4 \mathrm{~min}$, and finally $70 \%$ (A) isocratic for $5 \mathrm{~min}$ as postrun for reconditioning. Sample injection volume was adjusted to $10 \mu \mathrm{L}$. Total running time was $17 \mathrm{~min}$. All solutions of mobile phase were freshly prepared, filtered through $0.45 \mu \mathrm{m}$ Nylon filter under vacuum, and degassed by sonication for $20 \mathrm{~min}$ prior to use. The results were analysed using ChemStation software. The percentage of $\alpha$-mangostin in the extract was calculated based on the peak area.

2.3. Cell Culture. 3T3-L1 preadipocytes were grown in Dulbecco's Modified Eagle Media (DMEM) containing 10\% foetal bovine serum $(\mathrm{FBS}), 1 \%$ penicillin $(10.000 \mathrm{U} / \mathrm{mL})$, and $1 \%$ streptomycin $\left(10.000 \mu \mathrm{g} / \mathrm{mL}\right.$ supplemented in $37^{\circ} \mathrm{C}$ incubator in a humidified atmosphere of $5 \% \mathrm{CO}_{2}$ ). Cells were subcultured every 3 to 4 days at approximately $80 \%$ confluence.

2.4. Cell Viability. Cell viability was assessed by 3-(4,5-dimethylthiazol-2-yl)-2,5-diphenyltetrazolium bromide (MTT) assay. Mature adipocytes were seeded in 96-well plates and grown until confluence. $\alpha$-Mangostin was dissolved in dimethyl sulfoxide (DMSO) and treated for $48 \mathrm{~h}$. Our preliminary study showed that DMSO at a final concentration of $<0.1 \%$ in media did not affect cell viability or differentiation. Cells were then washed two times with phosphate buffer saline (PBS). $20 \mu \mathrm{L}$ of MTT stock solution $(5 \mathrm{mg} / \mathrm{mL})$ was added to each well and the plates were further incubated for $4 \mathrm{~h}$ at $37^{\circ} \mathrm{C} .100 \mu \mathrm{L}$ of DMSO was added to each well to solubilise the water-insoluble purple formazan crystals [41]. After $1 \mathrm{~h}$, the absorbency was measured at wavelength of $570 \mathrm{~nm}$ and reference wavelength of $630 \mathrm{~nm}$ with a microplate reader.

2.5. Adipocyte Differentiation. Cells were seeded onto 12well plates at a density of $2 \times 10^{4}$ cells/well. Two days after confluence (defined as day-0), cells were stimulated to differentiate with differentiation medium containing DMEM with $10 \%$ FBS and MDI [0.5 mM 3-isobutyl-1-methylxanthine (IBMX), $0.25 \mu \mathrm{M}$ dexamethasone, and $1 \mu \mathrm{g} / \mathrm{mL}$ insulin] for 2 days. In the course of screening adipocyte differentiationinhibitory activity, 3T3-L1 preadipocytes were treated with differentiation medium in the presence of various concentrations of test compound (10,25, and $50 \mu \mathrm{M}$ of $\alpha$-mangostin) at day-0. At day-2, differentiating medium was replaced with $10 \%$ FBS/DMEM medium containing $1 \mu \mathrm{g} / \mathrm{mL}$ insulin and incubated for another two days (day-4). Thereafter, the cells were maintained in 10\% FBS/DMEM medium for an additional 4 days (day-8) with medium changes every 2 days [42]. Adipocytes differentiation scheme was summarized in Table 1.

2.6. Oil Red O Staining. Eight days after the differentiation induction, cells were washed three times with PBS and fixed with $10 \%$ formalin for $1 \mathrm{~h}$ at room temperature. After fixation, cells were washed once with PBS and stained with freshly diluted Oil Red O solution (3 parts of $0.6 \%$ Oil Red O in isopropanol and 2 parts of water) for $1 \mathrm{~h}$. Cells were then washed twice with distilled water and visualised under a microscope. Images were collected on an Olympus (Tokyo, Japan) microscope. For quantitative analysis, Oil Red O stain was dissolved with isopropanol and optical density was measured at $520 \mathrm{~nm}$ by enzyme-linked immunosorbent assay (ELISA) plate reader [43].

2.7. Deoxy-[3H]-D-glucose Uptake Assay. Glucose uptake activity was analysed by measuring the uptake of radiolabelled glucose from the culture medium by adipocytes [42]. Briefly, the differentiated adipocytes, which were grown in 12well plates, were washed twice with serum-free DMEM and incubated for $3 \mathrm{~h}$ at $37^{\circ} \mathrm{C}$ with $1 \mathrm{~mL}$ of serum-free DMEM. The cells were then washed three times with Krebs-Ringer HEPES (KRPH) buffer (118 mM NaCl, $5 \mathrm{mM} \mathrm{KCl,} 1.3 \mathrm{mM}$ $\mathrm{CaCl}_{2}, 1.2 \mathrm{mM} \mathrm{MgSO}_{4}, 1.2 \mathrm{mM} \mathrm{KH}_{2} \mathrm{PO}_{4}$, and $30 \mathrm{mM}$ HEPES, $\mathrm{pH}$ 7.4) and incubated with $0.9 \mathrm{~mL}$ of $\mathrm{KRPH}$ buffer for $30 \mathrm{~min}$ at $37^{\circ} \mathrm{C}$. $\alpha$-Mangostin $(10,25$, and $50 \mu \mathrm{M})$ including the control was added, and the cells were incubated at $37^{\circ} \mathrm{C}$ for further $60 \mathrm{~min}$. Glucose uptake was initiated by the addition of $0.1 \mathrm{~mL}$ of KRPH buffer containing 2-deoxyD- $\left[{ }^{3} \mathrm{H}\right]$-glucose $(0.037 \mathrm{MBq}$; Perkin Elmer Inc., USA) and glucose $(0.001 \mathrm{mM})$. After $60 \mathrm{~min}$, the cells were washed three times with ice-cold PBSA to stop the glucose uptake. The cells were then lysed through incubation for $20 \mathrm{~min}$ at $37^{\circ} \mathrm{C}$ with $0.7 \mathrm{~mL}$ of $1 \%$ Triton $\mathrm{X}-100$. The radioactivity levels in the cell lysates were determined using a Tri-Carb 2700TR liquid scintillation counter, Packard Instrument Co. (USA). Samples from each lysate were counted and measured in triplicate.

2.8. Adipolysis Assay. Adipolysis assay kits (Cayman Chemical, USA) was used to study the adipolysis of triglycerides in differentiated 3T3-L1 cells. In order to perform the assay, the culture medium was carefully aspirated and replaced with fresh medium containing the various concentrations of $\alpha$ mangostin $(10,20$, and $50 \mu \mathrm{M})$. The isoproterenol solution was used as a positive control. Test compound ( $\alpha$-mangostin) and positive control were used to induce adipolysis and 


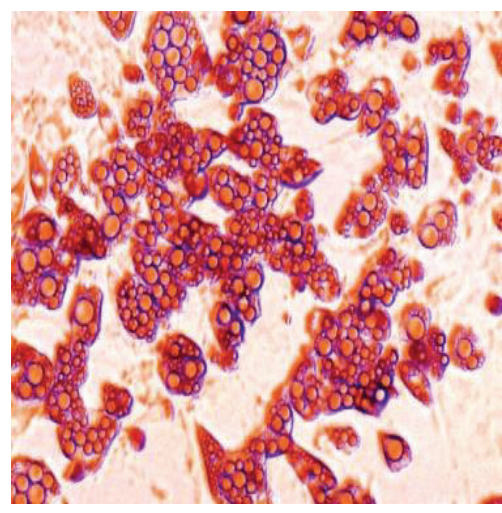

(a)

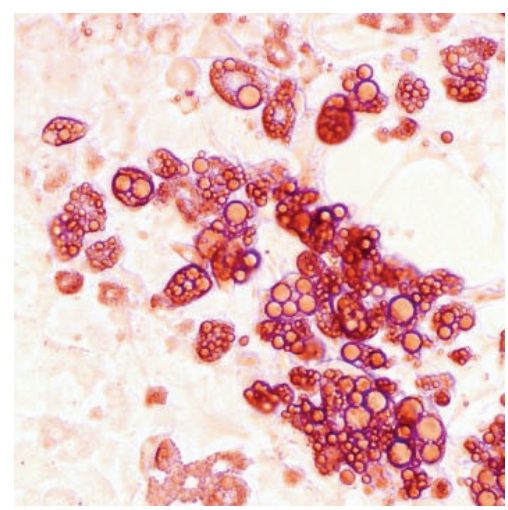

(d)

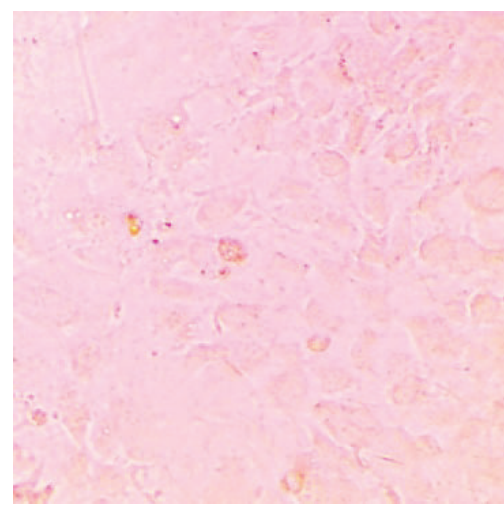

(b)

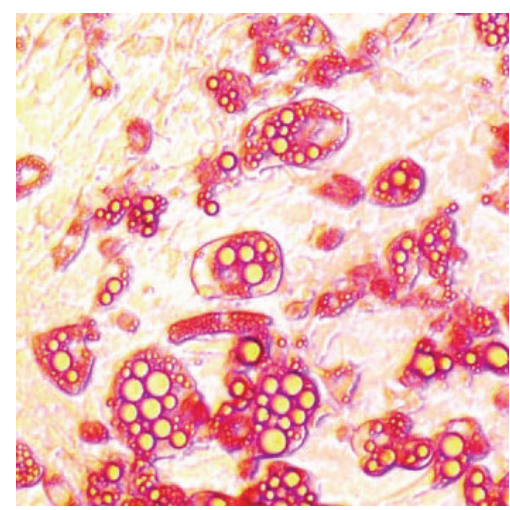

(e)

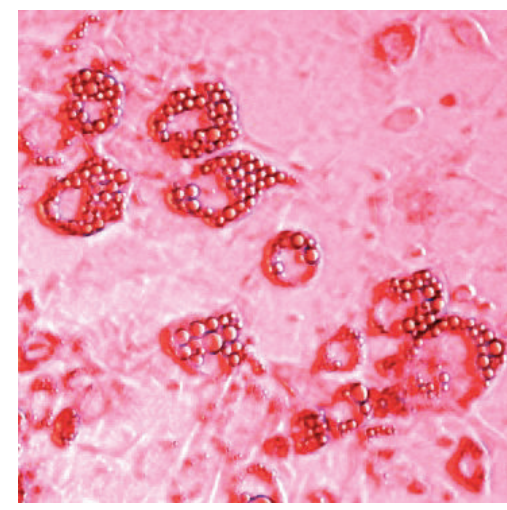

(c)

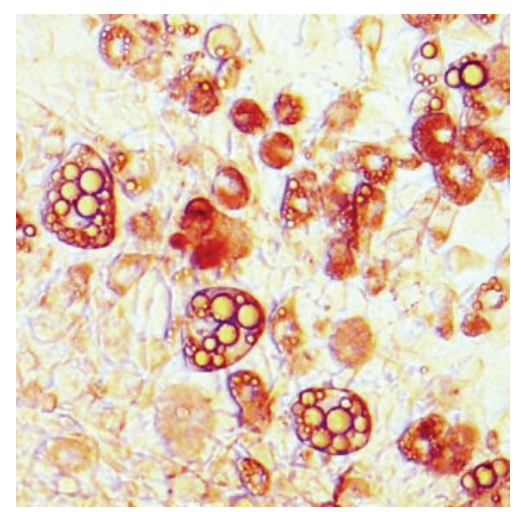

(f)

Figure 2: Stained fat droplets after differentiation programme (magnification 200x). (a) Insulin. (b) DMSO (negative control). (c) MDItreated cells. ((d)-(f)) $\alpha$-Mangostin, 10, 25, and $50 \mu \mathrm{M}$, respectively.

the amount of detectable free glycerol depend on the activity of the samples. Absorbance was finally measured at $540 \mathrm{~nm}$.

2.9. Quantitative Reverse Transcriptase Polymerase Chain Reaction (qRT-PCR) Analysis. Total RNA was extracted using Trizol reagent (Invitrogen, USA). The mRNA in the samples was reverse-transcribed into cDNA using QuantiTect Reverse Transcription (Qiagen) kit according to the manufacturer's instructions. The resulting cDNA was amplified by PCR using the following primer pairs: mouse PPAR (sense 5-TTTTCAAGGGTGCCAGTTTC-3 and antisense 5-AATCCTTGGCCCTCTGAGAT-3), GLUT4 (sense 5-CAGCTCTCAGGCATCAAT-3 and antisense 5-TCTACTAAGAGCACCGAG-3), and leptin (sense 5-GGAGGAATCCCTGCTCCAGC-3 and antisense 5-CTTCTCCTGAGGATACCTGG-3). The housekeeping beta-actin gene was amplified using the sense primer 5-ACACCCCAGCCATGTACG-3 and the antisense primer 5-TGGTGGTGAAGCTGTAGCC-3.

2.10. Statistical Analysis. Data are presented as means \pm standard error of three experiments. Data were analysed by ANOVA using SPPS version 19. A $P$-value of less than 0.05 was considered statistically significant.

\section{Results and Discussion}

3.1. Effect of $\alpha$-Mangostin on the Viability of 3T3-L1 Cells. The viability assay was used to determine any possible adverse effects of $\alpha$-mangostin (isolated from G. malaccensis) on the cells. The concentrations of $0,10,20$, and $50 \mu \mathrm{M}$ had no effect on the cell viability. Based on the MTT assay, the dosage of $100 \mu \mathrm{M}$ significantly $(P<0.05)$ decreased the cell viability and therefore was not used as treatment dose in this study.

3.2. Reduction of Intracellular Lipid Accumulation in 3T3-L1 Cells by $\alpha$-Mangostin. Eight days after treatment, preadipocytes differentiation was terminated and stained with Oil Red O. Fat droplets in these cells were visualised and photographed (Figure 2). Quantification of lipid accumulation by using UV spectrophotometer at $520 \mathrm{~nm}$ showed that cells treated with $\alpha$-mangostin reduced intracellular fat accumulation dose-dependently up to $44.4 \%$ relative to MDI-treated control cells at the dose of $50 \mu \mathrm{M}$ (Figure 3). Therefore, our results demonstrated that $\alpha$-mangostin added to the adipocyte inducer (IBMX, dexamethasone, and insulin) showed antiadipogenic activity as evidenced by decreased triglyceride accumulation in 3T3-L1 cells at all of the tested concentrations. This unique mechanism of decreased lipid formation [19] by $\alpha$-mangostin further prompted us to study the characteristic effect of $\alpha$-mangostin on adipocyte differentiation by using the quantitative RT-PCR. Since most studies have shown that PPAR $\gamma$ is one of the target genes in the induction of adipocyte differentiation [11], owing to the same fact, 


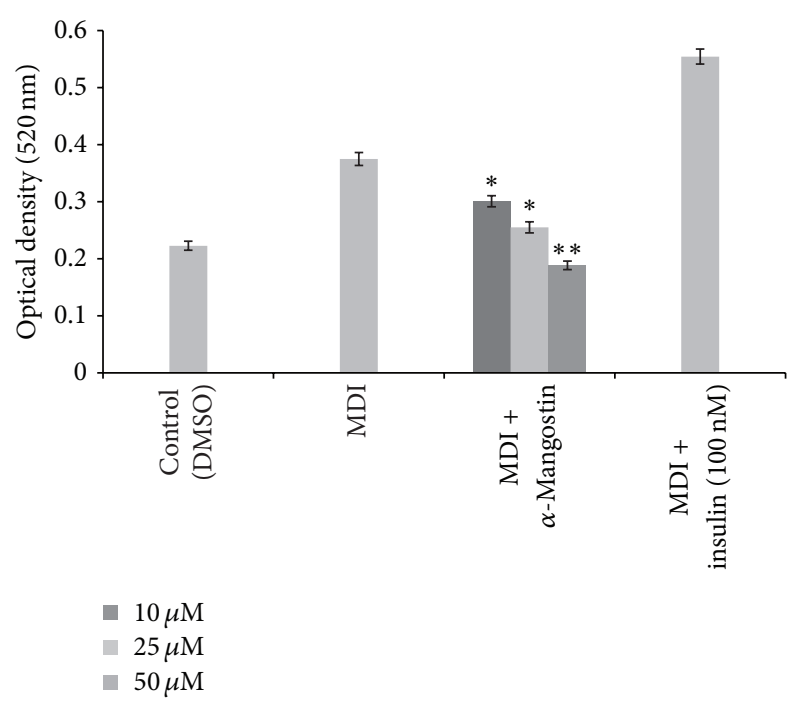

FIGURE 3: Effect of different concentration of $\alpha$-mangostin (10, $25,50 \mu \mathrm{M})$ on the differentiation of 3T3-L1 adipocytes. Data is represented as mean $\pm \mathrm{SD}$, with $n=3$ per group. ${ }^{*} P<0.05$, ${ }^{* *} P<0.01$ compared to MDI-treated cells.

the same gene was used to determine the mechanism for the inhibitory effect of $\alpha$-mangostin on the 3T3-L1 cells.

\subsection{Stimulation of Glucose Uptake in Mature 3T3-L1} Adipocytes by $\alpha$-Mangostin. As PPAR $\gamma$ ligands can affect the adipocyte differentiation and are reported to have an effect on glucose uptake in 3T3-L1 adipocytes [44], hence, the next part of this study was designed to evaluate the effect of $\alpha$-mangostin on the glucose uptake and insulin sensitivity. To determine 2-deoxy-D-glucose (2-DG) uptake stimulation by 3T3-L1 adipocytes, mature 3T3-L1 adipocytes were treated with $\alpha$-mangostin at the indicated concentrations $(10,25$, and $50 \mu \mathrm{M}$ ) for $60 \mathrm{~min}$, and then glucose uptake activity was assessed. The cells were treated with metformin $(1 \mathrm{mM})$ and sodium orthovanadate $(5 \mathrm{mM})$ as positive controls, and undifferentiated DMSO treated cells were used as a negative control for the assay. The results indicated that the $\alpha$-mangostin stimulated the glucose uptake in 3T3-L1 adipocytes. However, the insulin-induced glucose uptake was decreased by $\alpha$-mangostin at $50 \mu \mathrm{M}$. This finding was interesting since the test compound also reduced lipid formation at the same dose for up to $44.4 \%$ compared to the MDI-treated cells. This raised our attention to further evaluate the mechanism of related mRNA expression. Figure 4 illustrates the insulin-stimulated glucose uptake by the compounds. Levels of radioactivity in the cell lysates were determined using a liquid scintillation counter.

Adipocyte formation (adipogenesis), which occurs in several stages, is the development of mature fat cells from preadipocytes. This process includes alteration of cell shape, growth arrest, clonal expansion, and a complex sequence of changes in gene expression and storage of lipid [45]. Based on the above findings, it appears that our findings related to the effect of $\alpha$-mangostin on 3T3-L1 adipocytes were in

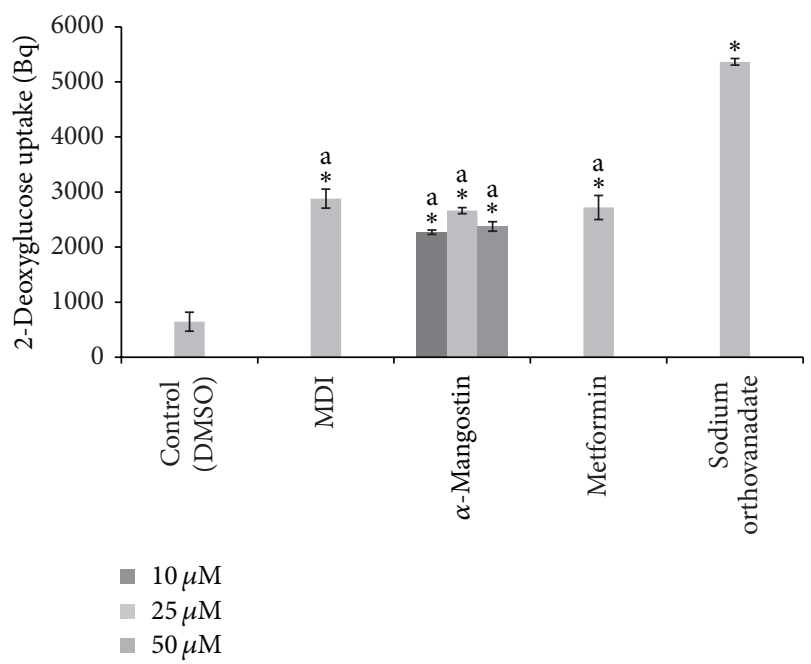

FIgURE 4: The effects of different concentration of $\alpha$-mangostin $(10,25,50 \mu \mathrm{M})$ in glucose uptake of 3T3-L1 adipocytes. Data is represented as mean $\pm \mathrm{SD}$, with $n=3$ per group. ${ }^{*} P<0.05$ compared to control group (DMSO treated cells), a = significant at indicated concentration.

agreement with several other reports $[46,47]$ stating that compound that inhibits adipocyte differentiation can also improve glucose uptake in the 3T3-L1 adipocytes.

In adipocytes, basal (cells treated with normal glucose without the presence of insulin and 2-deoxy- $\mathrm{D}-\left[{ }^{3} \mathrm{H}\right]$-glucose) and insulin-stimulated glucose uptake activity require a glucose transporter. Insulin can accelerate glucose entry by affecting the translocation of GLUT4 from intracellular stores to the plasma membrane [48]. In general, it is known that GLUT4 provides insulin-stimulated glucose transport in adipocytes [49]. Moreover, GLUT4 is expressed only in adipocytes and its expression is regulated by PPAR $\gamma$ [50]. Therefore, to go for any conclusion in this study, it seemed crucial to evaluate the expression of these genes in order to understand the mechanism of glucose uptake in the 3T3-L1 adipocytes.

3.4. Induction of Adipolysis by $\alpha$-Mangostin. Figure 5 shows that the adipolysis assay served as confirmatory results for the adipogenesis assay. The amount of glycerol released into the medium was proportional to the level of triglyceride storage and degree of adipolysis. It was found that cells treated with $\alpha$-mangostin increased the amount of free fatty acid released into the medium. It was further observed that the $\alpha$-mangostin result was similar with the isoproterenol $(10 \mu \mathrm{M})$, which was used as the positive control for the study. Lipolysis was measured by quantifying the glycerol released into the medium. Lipolysis in adipocytes is modulated in a stepwise fashion by several genes including the leptin. After this gene initiates the lipolysis pathway by releasing the fatty acids, glycerols are also released [51]. Moreover, it has been reported that plant extracts that inhibit the adipocyte differentiation of 3T3-L1 cells will also decrease the serum triglyceride levels in the adipose tissue [52]. These evidences 


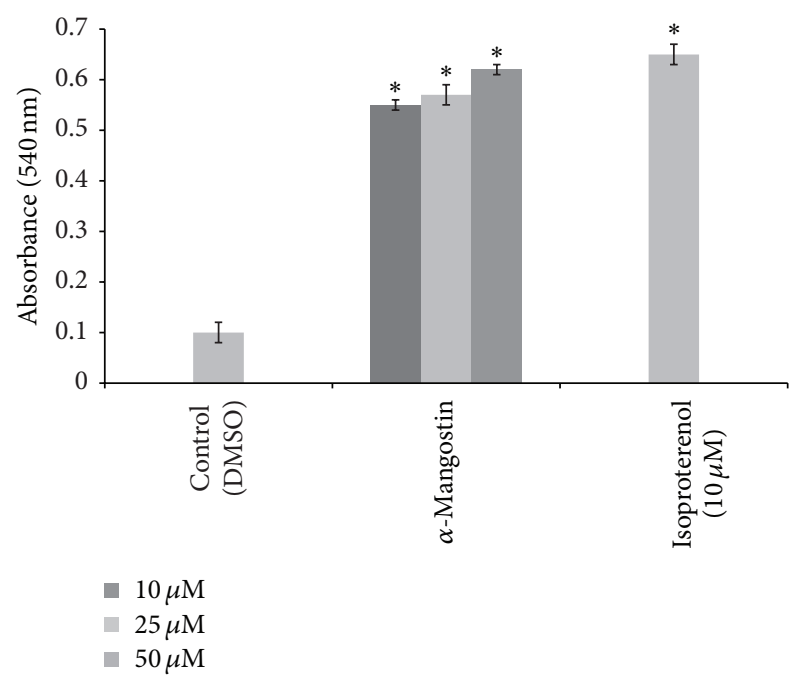

FIGURE 5: Glycerol release of different concentration of $\alpha$-mangostin $(10,25,50 \mu \mathrm{M})$ from the 3T3-L1 cells. Data is represented as mean \pm SD, with $n=3$ per group. ${ }^{*} P<0.05$ compared to control group (DMSO treated cells).

show that decreased adipocytes differentiation may trigger the adipocytes to release the triglyceride into the medium.

Generally, triglyceride can be converted into glycerol and free fatty acid when released into the medium. The data from the study showed that $\alpha$-mangostin enhanced lipolysis, and the efficacy of this action improved proportionally with the increase in concentration of $\alpha$-mangostin. The highest glycerol release level was observed for cells treated with $\alpha$ mangostin at $50 \mu \mathrm{M}$.

3.5. Inhibition of 3T3-L1 Adipocyte Differentiation Involving $P P A R \gamma$. To further assess the activity of $\alpha$-mangostin on PPAR $\gamma$ mRNA expression, 3T3-L1 preadipocytes were cultured with the indicated concentration of the compound $(25 \mu \mathrm{M})$ in the presence of MDI. This method can evaluate the stimulation or inhibitory effect of the test compound on adipocyte differentiation. As shown in Figure 6, cells treated with $\alpha$-mangostin showed reduced activity of PPAR $\gamma$ level when compared with the basal. Insulin $(100 \mathrm{nM})$ was used as the positive control [53]. Increased expression of PPAR $\gamma$ induces adipocyte differentiation in 3T3-L1 cells whereas the suppression of PPAR $\gamma$ expression blocks the lipid formation [12]. In this study, analysis of the gene expression demonstrated that the 3T3-L1 cells treated with $\alpha$-mangostin significantly downregulated the PPAR $\gamma$ expression. Therefore, we can deduce that the reduction in PPAR $\gamma$ may be the key step in the inhibition of adipocyte differentiation [22] in 3T3-L1 and that the targeting of PPAR $\gamma$ could be the main mechanism for blocking of adipocyte differentiation by the $\alpha$-mangostin.

3.6. Upregulation of Transcription of GLUT4 in 3T3-L1 Cells by $\alpha$-Mangostin. Afterward, we investigated the effects of $\alpha$ mangostin on the GLUT4 mRNA expression. As mentioned previously, the glucose uptake activity in adipocytes is related

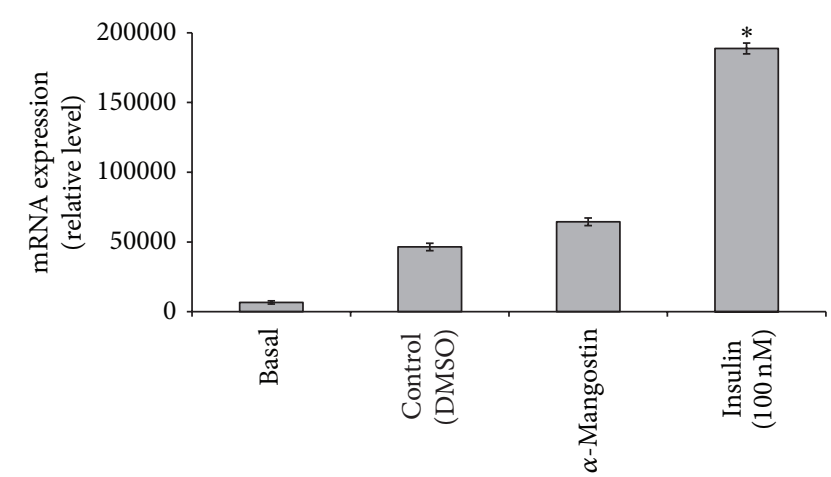

Figure 6: Effects of $\alpha$-mangostin $(25 \mu \mathrm{M})$ on PPARy mRNA expression. Data is represented as mean $\pm \mathrm{SD}$, with $n=3$ per group. ${ }^{*} P<0.05$ compared to control group (DMSO treated cells).

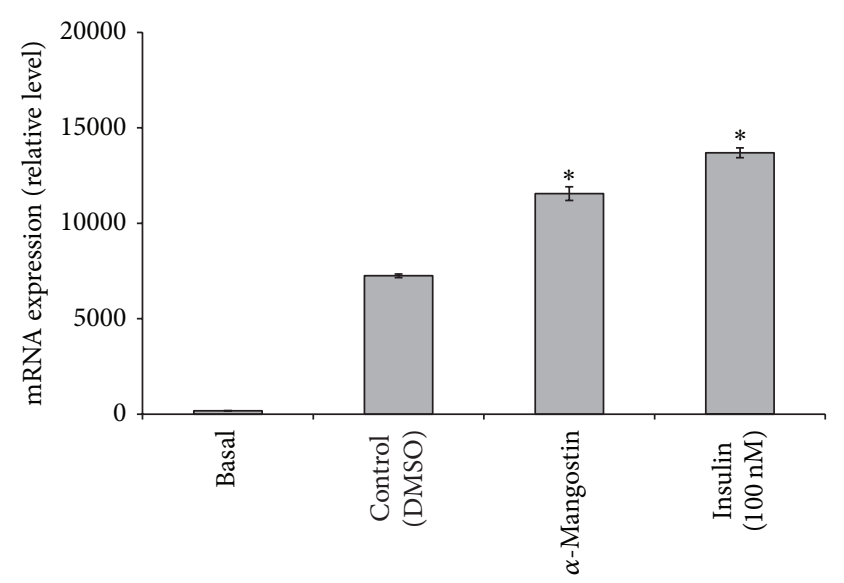

Figure 7: Effects of $\alpha$-mangostin $(25 \mu \mathrm{M})$ on GLUT4 mRNA expression. Data is represented as mean $\pm \mathrm{SD}$, with $n=3$ per group. ${ }^{*} P<0.05$ compared to control group (DMSO treated cells).

to the expression of glucose transporters. In this study, it was observed that all the GLUT4 mRNA expression in fully differentiated adipocytes increased significantly after treatment with $\alpha$-mangostin (Figure 7). This result demonstrated that the $\alpha$-mangostin promoted glucose uptake in 3T3-L1 adipocytes via the upregulation of GLUT4 expression.

GLUT4, which transports glucose from blood into tissue, is the principal glucose transporter among several isotypes of glucose transporters in insulin-sensitive tissues such as skeletal muscle and adipocytes [47]. Decrease in the translocation of GLUT4 to the plasma membrane has been found to be the major cause of insulin resistance [46], and it is required to activate GLUT4 in skeletal muscle to improve insulin resistance and to maintain blood glucose homeostasis. Metformin, which is one of the widely used antidiabetic drugs, can enhance the insulin-stimulated glucose uptake by increasing the cell surface GLUT4 content [11]. In this study, to assess whether the increased glucose uptake stimulated by $\alpha$-mangostin was due to the translocation of GLUT4, the amount of GLUT4 expression present in the cells was measured by using the quantitative qRT-PCR. 


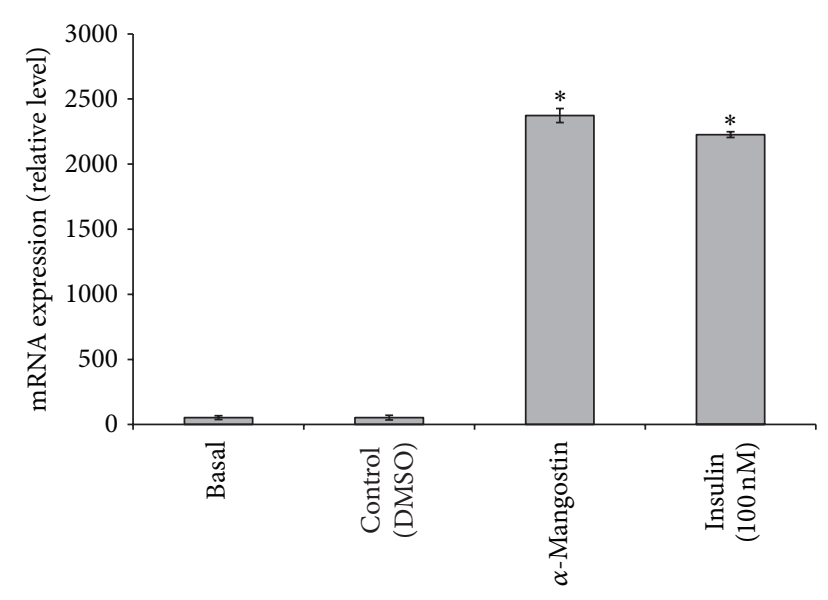

FIGURE 8: Effects of $\alpha$-mangostin ( $25 \mu \mathrm{M})$ on leptin mRNA expression. Data is represented as mean $\pm \mathrm{SD}$, with $n=3$ per group. ${ }^{*} P<0.05$ compared to control group (DMSO treated cells).

As shown previously, the $\alpha$-mangostin treatment significantly $(P<0.05)$ upregulated the mRNA expression of GLUT4 gene in fully differentiated adipocytes. This result indicates that the $\alpha$-mangostin accelerated basal and insulinmediated glucose uptake by upregulating the GLUT4 expression. Decreased GLUT4 expression in adipose tissue is associated with obesity and type 2 diabetes in humans [54]. Thus, it is important to use a compound that could improve glucose uptake and stimulate GLUT4 expression.

3.7. Role of $\alpha$-Mangostin in Leptin Expression. Finally, in the gene expression analysis, we evaluated the effect of $\alpha$ mangostin on leptin expression to signify the free fatty acid release from the cells into the medium. Analysis with $\alpha$ mangostin $(25 \mu \mathrm{M})$ showed that the compound increased the leptin expression and the result was similar with insulin $(100 \mathrm{nM})$ that was used as the positive control for the study (Figure 8 ). This result suggests that $\alpha$-mangostin treatment may release the free fatty acid into the medium, which was confirmed by the leptin mRNA expression. In obese individuals, plasma leptin and free fatty acid are both elevated. Since free fatty acid also reduces plasma leptin levels in the in vitro study [5], it has been speculated that obesity may be caused by the abnormality in the leptin-reduction mechanism of free fatty acids. Alternatively, leptin resistance, which has been considered to be present in obesity, might overcome the decrease in leptin induced by free fatty acid [55].

\section{Conclusion}

In summary, the present study has shown that $\alpha$-mangostin isolated from G. malaccensis reduces lipid accumulation with decreased PPAR $\gamma$ expression as well as stimulating the glucose uptake and free fatty acid release from the cells via GLUT4 and leptin expression. Taken together, these results indicate that $\alpha$-mangostin derived from $G$. malaccensis may be a candidate for preventing metabolic disorders such as obesity particularly among diabetics.

\section{Conflict of Interests}

The authors declare that there is no conflict of interests.

\section{Acknowledgments}

This work was supported by the International Islamic University Malaysia through EDWB11-018-0496 and Ministry of Science, Technology and Innovation through the e-Science Fund (02-01-08-SF0110).

\section{References}

[1] S. Devalaraja, S. Jain, and H. Yadav, "Exotic fruits as therapeutic complements for diabetes, obesity and metabolic syndrome," Food Research International, vol. 44, no. 7, pp. 1856-1865, 2011.

[2] Q.-Q. Tang, T. C. Otto, and M. Daniel Lane, "Mitotic clonal expansion: a synchronous process required for adipogenesis," Proceedings of the National Academy of Sciences of the United States of America, vol. 100, no. 1, pp. 44-49, 2003.

[3] K. Lois and S. Kumar, "Obesity and diabetes," Endocrinologia y Nutricion, vol. 56, no. 4, pp. 38-42, 2009.

[4] H. J. Park, J.-Y. Cho, M. K. Kim et al., "Anti-obesity effect of Schisandra chinensis in 3T3-L1 cells and high fat diet-induced obese rats," Food Chemistry, vol. 134, no. 1, pp. 227-234, 2012.

[5] A. R. Nawrocki and P. E. Scherer, "Keynote review: the adipocyte as a drug discovery target," Drug Discovery Today, vol. 10, no. 18, pp. 1219-1230, 2005.

[6] J. Eric and T. Luc, "Obesity," Molecular Aspects of Medicine, vol. 18, no. 4, pp. 247-305, 1997.

[7] B. M. Spiegelman and J. S. Flier, "Obesity and the regulation of energy balance," Cell, vol. 104, no. 4, pp. 531-543, 2001.

[8] J. W. Yun, "Possible anti-obesity therapeutics from nature-a review," Phytochemistry, vol. 71, no. 14-15, pp. 1625-1641, 2010.

[9] M. E. F. Vázquez-Vela, N. Torres, and A. R. Tovar, "White adipose tissue as endocrine organ and its role in obesity," Archives of Medical Research, vol. 39, no. 8, pp. 715-728, 2008.

[10] R. P. Brun and B. M. Spiegelman, "PPARgamma and the molecular control of adipogenesis," Journal of Endocrinology, vol. 155, no. 2, pp. 217-218, 1997.

[11] S.-S. Choi, B.-Y. Cha, K. Iida et al., "Artepillin C, as a PPAR $\gamma$ ligand, enhances adipocyte differentiation and glucose uptake in 3T3-L1 cells," Biochemical Pharmacology, vol. 81, no. 7, pp. 925-933, 2011.

[12] C. Huang, Y. Zhang, Z. Gong et al., "Berberine inhibits 3T3L1 adipocyte differentiation through the PPAR $\gamma$ pathway," Biochemical and Biophysical Research Communications, vol.348, no. 2, pp. 571-578, 2006.

[13] R. T. Watson and J. E. Pessin, "GLUT4 translocation: the last 200 nanometers," Cellular Signalling, vol. 19, no. 11, pp. 2209-2217, 2007.

[14] T. Akiba, K. Yaguchi, K. Tsutsumi et al., "Inhibitory mechanism of caffeine on insulin-stimulated glucose uptake in adipose cells," Biochemical Pharmacology, vol. 68, no. 10, pp. 1929-1937, 2004.

[15] J. S. Flier, "Obesity wars: molecular progress confronts an expanding epidemic," Cell, vol. 116, no. 2, pp. 337-350, 2004.

[16] S. K. Fried, M. R. Ricci, C. D. Russell, and B. Laferrère, "Regulation of leptin production in humans," Journal of Nutrition, vol. 130, no. 12, pp. 3127-3131, 2000. 
[17] S. Galic, J. S. Oakhill, and G. R. Steinberg, "Adipose tissue as an endocrine organ," Molecular and Cellular Endocrinology, vol. 316, no. 2, pp. 129-139, 2010.

[18] B. S. Jena, G. K. Jayaprakasha, R. P. Singh, and K. K. Sakariah, "Chemistry and biochemistry of (-)-hydroxycitric acid from Garcinia," Journal of Agricultural and Food Chemistry, vol. 50, no. 1, pp. 10-22, 2002.

[19] N. Hasegawa, "Garcinia extract inhibits lipid droplet accumulation without affecting adipose conversion in 3T3-L1 cells," Phytotherapy Research, vol. 15, no. 2, pp. 172-173, 2001.

[20] V. Badmaev, M. Majeed, A. A. Conte et al., "Garcinia cambogia for weight loss," Journal of the American Medical Association, vol. 282, no. 3, pp. 233-235, 1999.

[21] S. B. Heymsfield, D. B. Allison, J. R. Vasselli, A. Pietrobelli, D. Greenfield, and C. Nunez, "Garcinia cambogia (hydroxycitric acid) as a potential antiobesity agent: a randomized controlled trial," The Journal of the American Medical Association, vol. 280, no. 18, pp. 1596-1600, 1998.

[22] M.-S. Kim, J.-K. Kim, D.-Y. Kwon, and R. Park, "Antiadipogenic effects of Garcinia extract on the lipid droplet accumulation and the expression of transcription factor., BioFactors, vol. 22, no. 1-4, pp. 193-196, 2004.

[23] C. Roongpisuthipong, R. Kantawan, and W. Roongpisuthipong, "Reduction of adipose tissue and body weight: effect of water soluble calcium hydroxycitrate in Garcinia atroviridis on the short term treatment of obese women in Thailand," Asia Pacific Journal of Clinical Nutrition, vol. 16, no. 1, pp. 25-29, 2007.

[24] I. Onakpoya, S. K. Hung, R. Perry, B. Wider, and E. Ernst, "The use of Garcinia extract (hydroxycitric acid) as a weight loss supplement: a systematic review and meta-analysis of randomised clinical trials," Journal of Obesity, vol. 2011, Article ID 509038, 9 pages, 2011.

[25] K. Varalakshmi, C. Sangeetha, A. Shabeena, S. Sunitha, and J. Vapika, "Antimicrobial and cytotoxic effects of Garcinia indica fruit rind extract," American-Eurasian Journal of Agricultural \& Environmental Sciences, vol. 7, pp. 652-656, 2010.

[26] M. Taher, D. Susanti, M. F. Rezali et al., "Apoptosis, antimicrobial and antioxidant activities of phytochemicals from Garcinia malaccensis Hk.f," Asian Pacific Journal of Tropical Medicine, vol. 5, no. 2, pp. 136-141, 2012.

[27] Y. Sakagami, M. Iinuma, K. G. N. P. Piyasena, and H. R. W. Dharmaratne, "Antibacterial activity of $\alpha$-mangostin against vancomycin resistant Enterococci (VRE) and synergism with antibiotics," Phytomedicine, vol. 12, no. 3, pp. 203-208, 2005.

[28] Y.-W. Chin and D. Kinghorn, "Structural characterization, biological effects, and synthetic studies on xanthones from mangosteen (Garcinia mangostana), a popular botanical dietary supplement," Mini-Reviews in Organic Chemistry, vol. 5, no. 4, pp. 355-364, 2008.

[29] S. H. Liu, L. T. Lee, N. Y. Hu et al., "Effects of alpha-mangostin on the expression of anti-inflammatory genes in U937 cells," Chinese Medicine, vol. 7, article 19, 2012.

[30] H.-Y. Jang, O.-K. Kwon, S.-R. Oh, H.-K. Lee, K.-S. Ahn, and Y.W. Chin, "Mangosteen xanthones mitigate ovalbumin-induced airway inflammation in a mouse model of asthma," Food and Chemical Toxicology, vol. 50, no. 11, pp. 4042-4050, 2012.

[31] F. Gutierrez-Orozco, C. Chitchumroonchokchai, G. B. Lesinski, S. Suksamrarn, and M. L. Failla, " $\alpha$-Mangostin: antiinflammatory activity and metabolism by human cells," Journal of Agricultural and Food Chemistry, vol. 61, no. 16, pp. 38913900, 2013.
[32] C. Chitchumroonchokchai, J. M. Thomas-Ahner, J. Li et al., "Anti-tumorigenicity of dietary $\alpha$-mangostin in an HT-29 colon cell xenograft model and the tissue distribution of xanthones and their phase II metabolites," Molecular Nutrition and Food Research, vol. 57, no. 2, pp. 203-211, 2013.

[33] H.-F. Chang, W.-T. Huang, H.-J. Chen, and L.-L. Yang, "Apoptotic effects of $\gamma$-mangostin from the fruit hull of Garcinia mangostana on human malignant glioma cells," Molecules, vol. 15, no. 12, pp. 8953-8966, 2010.

[34] A. Krajarng, Y. Nakamura, S. Suksamrarn, and R. Watanapokasin, " $\alpha$-Mangostin induces apoptosis in human chondrosarcoma cells through downregulation of ERK/JNK and Akt signaling pathway," Journal of Agricultural and Food Chemistry, vol. 59, no. 10, pp. 5746-5754, 2011.

[35] H. Kurose, M.-A. Shibata, M. Iinuma, and Y. Otsuki, "Alterations in cell cycle and induction of apoptotic cell death in breast cancer cells treated with $\alpha$-mangostin extracted from mangosteen pericarp," Journal of Biomedicine \& Biotechnology, vol. 2012, Article ID 672428, 9 pages, 2012.

[36] H. Doi, M.-A. Shibata, E. Shibata et al., "Panaxanthone isolated from pericarp of Garcinia mangostana L. suppresses tumor growth and metastasis of a mouse model of mammary cancer," Anticancer Research, vol. 29, no. 7, pp. 2485-2495, 2009.

[37] A.-C. Chao, Y.-L. Hsu, C.-K. Liu, and P.-L. Kuo, “ $\alpha$-mangostin, a dietary xanthone, induces autophagic cell death by activating the AMP-activated protein kinase pathway in glioblastoma cells," Journal of Agricultural and Food Chemistry, vol. 59, no. 5, pp. 2086-2096, 2011.

[38] M.-A. Shibata, M. Iinuma, J. Morimoto et al., " $\alpha$-Mangostin extracted from the pericarp of the mangosteen (Garcinia mangostana Linn) reduces tumor growth and lymph node metastasis in an immunocompetent xenograft model of metastatic mammary cancer carrying a p53 mutation," BMC Medicine, vol. 9, article 69, 2011.

[39] J. J. Johnson, S. M. Petiwala, D. N. Syed et al., " $\alpha$-mangostin, a xanthone from mangosteen fruit, promotes cell cycle arrest in prostate cancer and decreases xenograft tumor growth," Carcinogenesis, vol. 33, no. 2, pp. 413-419, 2012.

[40] A. A. Elsaid Ali, M. Taher, and F. Mohamed, "Microencapsulation of alpha-mangostin into PLGA microspheres and optimization using response surface methodology intended for pulmonary delivery," Journal of Microencapsulation, vol. 30, no. 8, pp. 728-740, 2013.

[41] T. Mosmann, "Rapid colorimetric assay for cellular growth and survival: application to proliferation and cytotoxicity assays," Journal of Immunological Methods, vol. 65, no. 1-2, pp. 55-63, 1983.

[42] D. Susantia, M. Z. A. M. Amiroudineb, M. F. Rezalic, and M. Taherb, "Friedelin and lanosterol from Garcinia prainiana stimulated glucose uptake and adipocytes differentiation in 3T3-L1 adipocytes," Natural Product Research, vol. 27, no. 4-5, pp. 417-424, 2013.

[43] E. Shin, K.-M. Choi, H.-S. Yoo, C.-K. Lee, B. Y. Hwang, and M. K. Lee, "Inhibitory effects of coumarins from the stem barks of Fraxinus rhynchophylla on adipocyte differentiation in 3T3-L1 cells," Biological and Pharmaceutical Bulletin, vol. 33, no. 9, pp. 1610-1614, 2010.

[44] S. R. Tafuri, "Troglitazone enhances differentiation, basal glucose uptake, and Glut1 protein levels in 3T3-L1 adipocytes," Endocrinology, vol. 137, no. 11, pp. 4706-4712, 1996. 
[45] M. I. Lefterova and M. A. Lazar, "New developments in adipogenesis," Trends in Endocrinology and Metabolism, vol. 20, no. 3, pp. 107-114, 2009.

[46] D. T. Ha, T. N. Trung, T. T. Phuong, N. Yim, Q. C. Chen, and K. Bae, "The selected flavonol glycoside derived from Sophorae Flos improves glucose uptake and inhibits adipocyte differentiation via activation AMPK in 3T3-L1 cells," Bioorganic and Medicinal Chemistry Letters, vol. 20, no. 20, pp. 6076-6081, 2010.

[47] S. Anand, V. S. Muthusamy, S. Sujatha et al., "Aloe emodin glycosides stimulates glucose transport and glycogen storage through PI3K dependent mechanism in L6 myotubes and inhibits adipocyte differentiation in 3T3L1 adipocytes," FEBS Letters, vol. 584, no. 14, pp. 3170-3178, 2010.

[48] M. J. Thomson, M. G. Williams, and S. C. Frost, "Development of insulin resistance in 3T3-L1 adipocytes," The Journal of Biological Chemistry, vol. 272, no. 12, pp. 7759-7764, 1997.

[49] W. Shang, Y. Yang, B. Jiang et al., "Ginsenoside Rb1 promotes adipogenesis in 3T3-L1 cells by enhancing PPAR $\gamma 2$ and C/EBP $\alpha$ gene expression," Life Sciences, vol. 80, no. 7, pp. 618-625, 2007.

[50] F. M. Gregoire, C. M. Smas, and H. S. Sul, "Understanding adipocyte differentiation," Physiological Reviews, vol. 78, no. 3, pp. 783-809, 1998.

[51] J.-H. Lee, M.-H. Moon, J.-K. Jeong et al., "Sulforaphane induced adipolysis via hormone sensitive lipase activation, regulated by AMPK signaling pathway," Biochemical and Biophysical Research Communications, vol. 426, no. 4, pp. 492-497, 2012.

[52] K. Hata, K. Hiwatashi, M. Itoh et al., "Inhibitory effects of lupeol on 3T3-L1 preadipocyte differentiation," Phytochemistry Letters, vol. 1, no. 4, pp. 191-194, 2008.

[53] D. Guo and D. B. Donner, "Tumor necrosis factor promotes phosphorylation and binding of insulin receptor substrate 1 to phosphatidylinositol 3-kinase in 3T3-L1 adipocytes," The Journal of Biological Chemistry, vol. 271, no. 2, pp. 615-618, 1996.

[54] L. Granlund, J. I. Pedersen, and H. I. Nebb, "Impaired lipid accumulation by trans10, cis12 CLA during adipocyte differentiation is dependent on timing and length of treatment," Biochimica et Biophysica Acta-Molecular and Cell Biology of Lipids, vol. 1687, no. 1-3, pp. 11-22, 2005.

[55] M. Shintani, H. Nishimura, S. Yonemitsu et al., "Downregulation of leptin by free fatty acids in rat adipocytes: effects of triacsin C, palmitate, and 2-bromopalmitate," Metabolism: Clinical and Experimental, vol. 49, no. 3, pp. 326-330, 2000. 


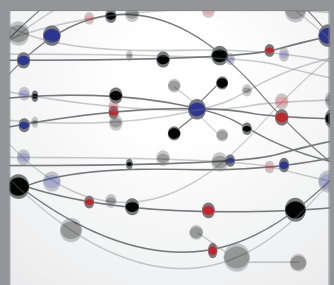

The Scientific World Journal
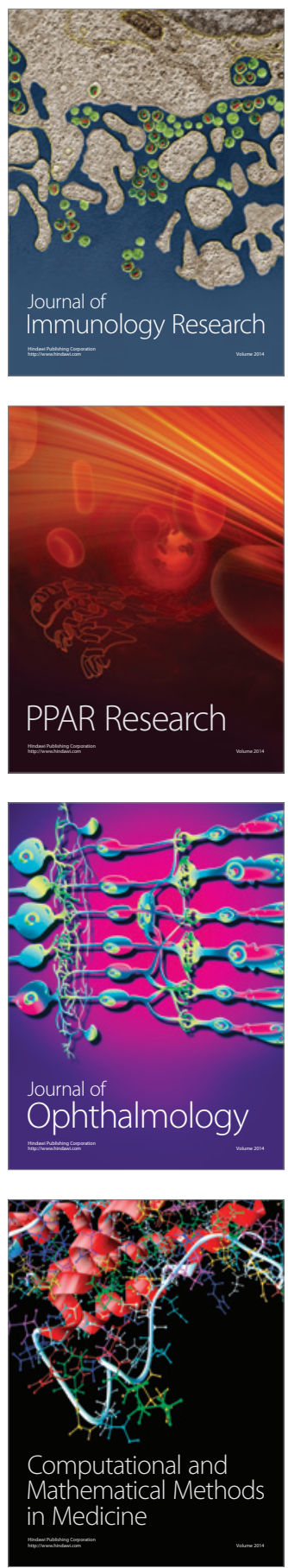

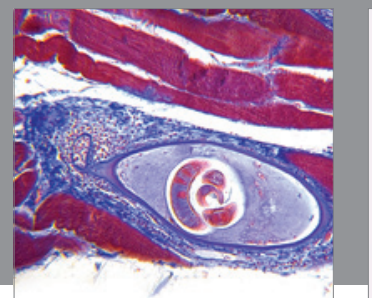

Gastroenterology

Research and Practice
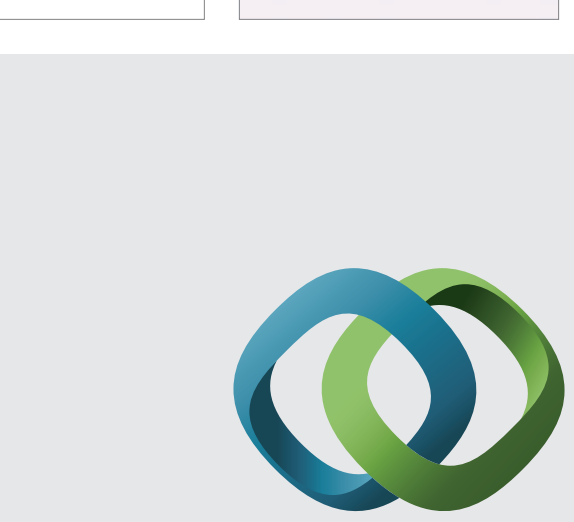

\section{Hindawi}

Submit your manuscripts at

http://www.hindawi.com
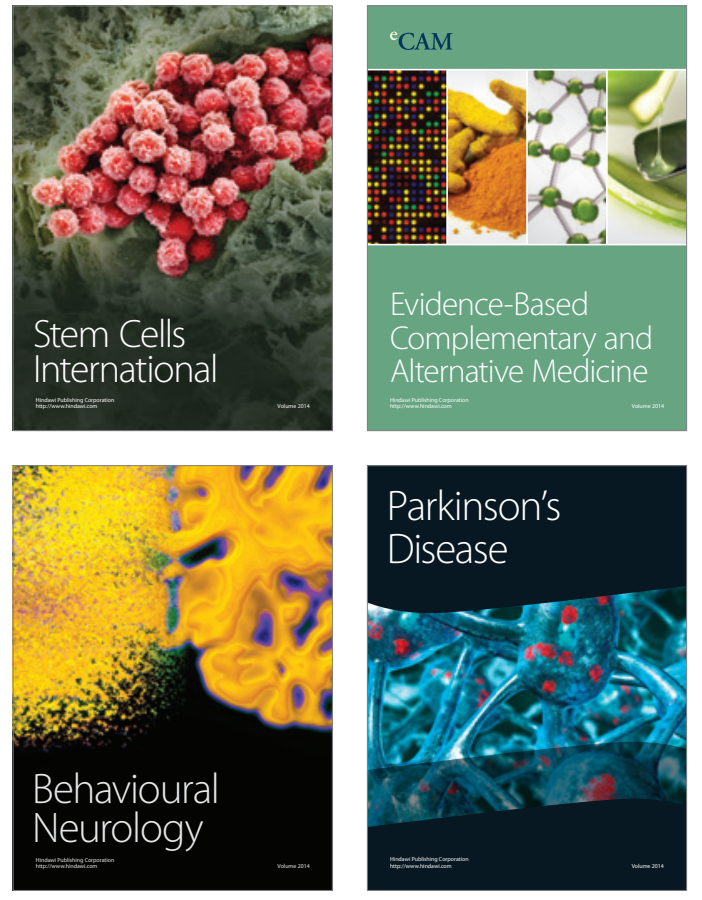
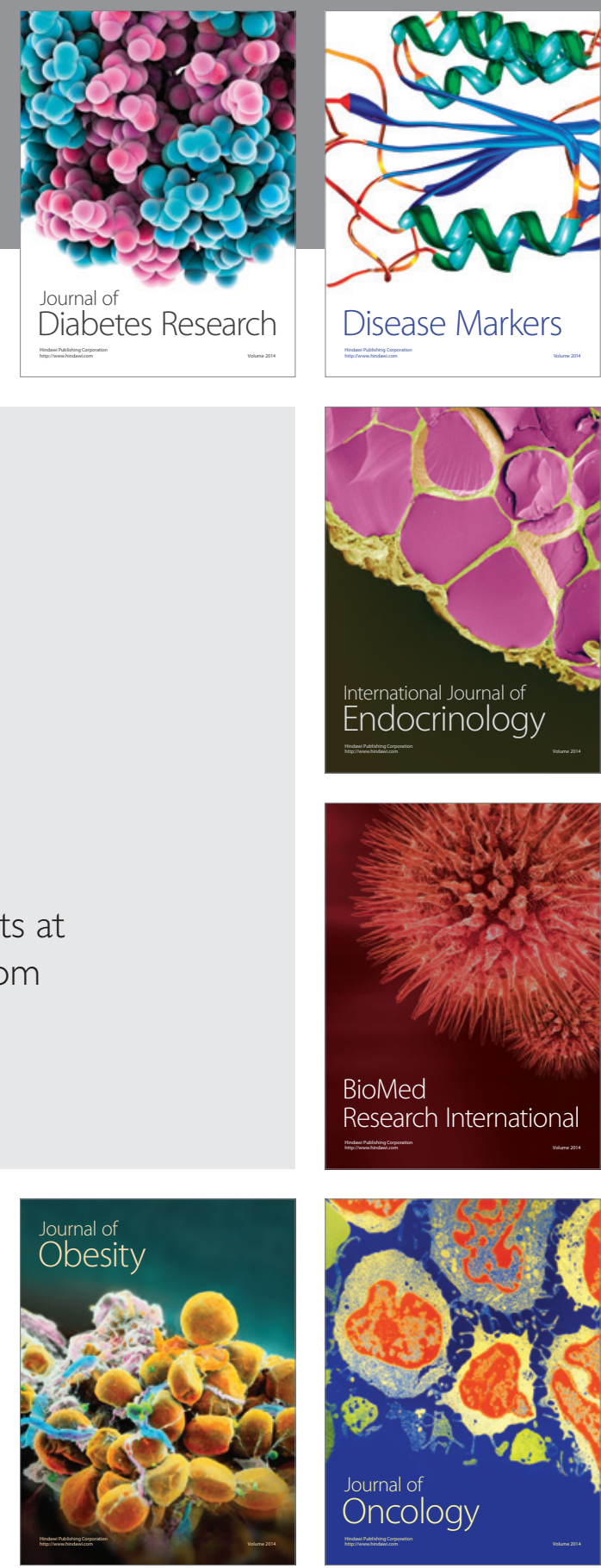

Disease Markers
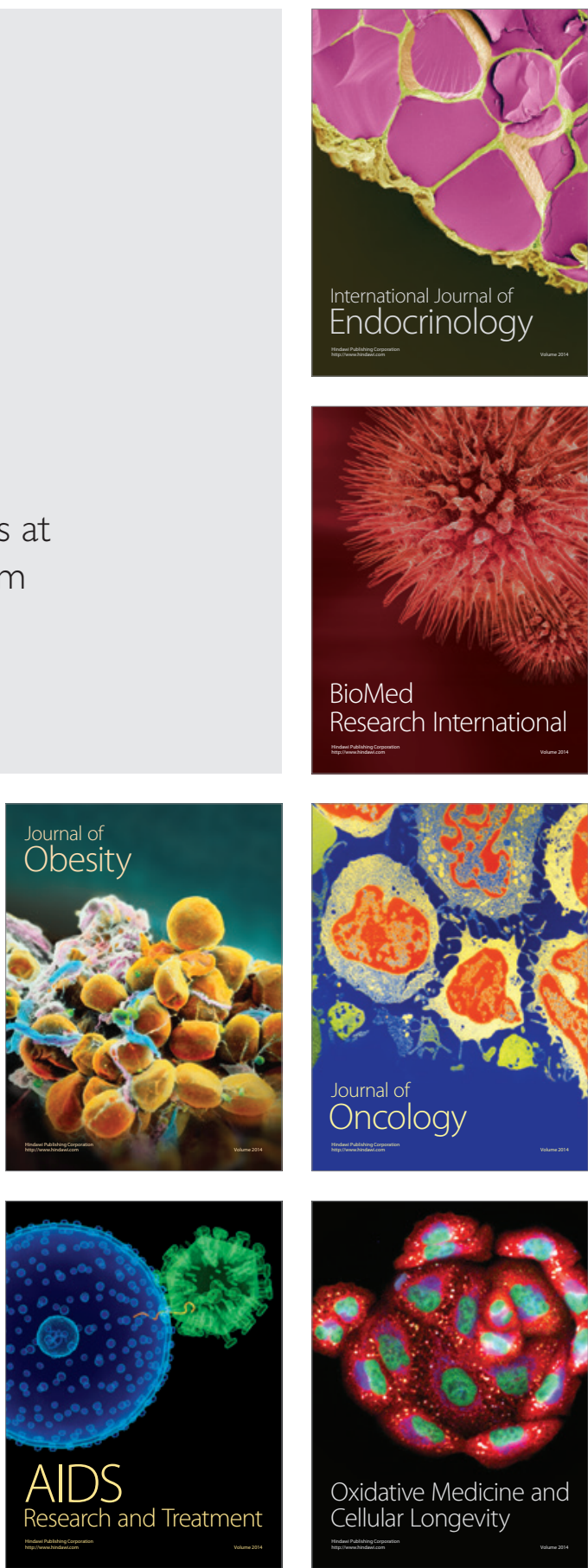